\title{
Effect of the Monocyte Locomotion Inhibitory Factor (MLIF) a Natural Anti-Inflammatory Produced by $E$. histolytica on Apoptosis in Human CD4+ T Lymphocytes
}

\author{
Sara Rojas-Dotor ${ }^{1}$, Liliana Vargas-Neri², Francisco Blanco-Favela ${ }^{1}$ \\ ${ }^{1}$ Unidad de Investigación Médica en Inmunología, Hospital de Pediatría, Centro Médico Nacional Siglo XXI Instituto Mexicano del \\ Seguro Social, México City, México; ${ }^{2}$ Facultad de Química, Universidad Nacional Autónoma de México, México City, México. \\ Email: srdotor@yahoo.com.mx
}

Received June $4^{\text {th }}, 2011$; revised July $28^{\text {th }}, 2011$; accepted August $16^{\text {th }}, 2011$.

\begin{abstract}
Apoptosis prevents the extravasation of intracellular material and the subsequent inflammatory response. Currently, it is not known whether Monocyte Locomotion Inhibitor Factor (MLIF), an anti-inflammatory pentapeptide, induces programmed cell death. We evaluated the effect of MLIF on extrinsic and intrinsic apoptosis pathways human CD4+ T lymphocytes. Cells were cultured for $24 \mathrm{~h}$ in RPMI-1640 medium alone (control) or in RPMI medium containing MLIF alone, PMA alone, PMA + MLIF or actinomycin D. Annexin V/propidium iodide-stained cells in early apoptosis showed that cells treated with MLIF or PMA + MLIF were not significantly different from control cells in medium; in contrast, cells treated with PMA or PMA + MLIF demonstrated significant differences from the control in delayed apoptosis. Cytochrome $c$ and caspase 3 levels in cells treated with MLIF showed no significant differences from control cells, however, compared to the control, cells treated with PMA and PMA + MLIF exhibited a significant increase in cytochrome $c$ and caspase 3 levels, which demonstrates that this weak induction of cell death is regulated by the intrinsic pathway of apoptosis. The Fas receptor was not detected in cell culture with any of the treatments employed, suggesting that the extrinsic pathway of apoptosis is not involved. The MLIF per se does not induce apoptosis in human CD4+ T lymphocytes; there may be an additional effect of PMA + MLIF producing the low levels of cell death recorded in the late apoptosis phase. MLIF acts as a natural, biological anti-inflammatory compound produced in axenic cultures of E. histolytica that does not cause apoptosis or elicit an immune response due to its small size, which could make it a strong candidate for future clinical applications.
\end{abstract}

Keywords: MLIF, Apoptosis, Anti-Inflammatory, Intrinsic Pathway, Extrinsic Pathway

\section{Introduction}

$\mathrm{T}$ lymphocytes constitute an essential part of the immune system. Their generation, activation, proliferation and survival are subject to tight regulation by several extracellular factors including cytokines, MHC-antigen complexes and co-stimulatory ligands; however, internal or external stimuli, such as over-stimulation, cytotoxicity or time, can lead to death. The balanced interplay between these factors determines the fate of a T cell [1-3]. Once the cytotoxicity or over-stimulation occurs, $\mathrm{T}$ cells become apoptosis-sensitive, leading to the death of most cells and the survival of only a few memory T cells. Like other cells, $\mathrm{T}$ cells are dependent on signals from their environment for their survival; apoptosis thus represents a tightly regulated process by which lymphocyte homeostasis is controlled, and the generation of autoreactive cells is prevented [4-6].

Apoptosis or programmed cell death, which plays a central role in the normal development of multicellular organisms, is essential for $\mathrm{T}$ cell function, the regulation of B cells, the suppression of autoimmunity, the control infections, as well as immune surveillance and homeostasis $[7,8]$. One of the most important physiological characteristics of cell death by apoptosis is no inflammatory response. Key proteins are released into the cytosol by mitochondria (intrinsic pathway of apoptosis) or as a 
consequence of activating a cell death receptor on the cell surface (extrinsic pathway of apoptosis) [9]. Both signalling pathways can converge upon the activation cascade of effector caspases. Activation of the proapoptotic proteins of the Bcl-2 family leads to the formation of a pore in the outer membrane of mitochondria, which allows the release of proteins of including cytochrome $\mathrm{c}$ from mitochondrial intramembranous space into the cytosol; activates the apoptosome complex and caspase 9; and finally activates effector caspases, such as caspase-3-6 and 7 which triggers the final stages of apoptosis. In contrast, when a cell dies via necrosis, the cytoplasmic contents are released into the interstitial space, exposing a large number of antigens and triggering a strong inflammatory response $[10,11]$.

The protozoan parasite Entamoeba histolytica (E. histolytica) produces an anti-inflammatory pentapeptide (Met-Gln-Cys-Asn-Ser; MLIF) that inhibits human monocyte locomotion in vivo and in vitro [12]. MLIF depresses production of nitric oxide reactive intermediates by human monocytes and neutrophils, decreases the expression of adhesion molecules (VL-4 in monocytes and VCAM-1 in the vascular endothelium), and inhibits delayed hypersensitivity reactions in gerbils and guinea pigs [13-15]. The scrambled pentapeptide (MLIF, GlnCys-Met-Ser-Asn); showed no anti-inflammatory properties [16]. This anti-inflammatory effect could be attributed to the chemical activity of the peptide. Ongoing studies in quantum chemistry have revealed that a pharmacophore group in the MLIF sequence (... Cys-AsnSer) could be responsible for most of the anti-inflammatory properties of this molecule [17]. Currently it is unknown whether MLIF may have some involvement with the mechanisms of programmed cell death. The aim of this study was to evaluate the effect of anti-inflammatory MLIF on apoptosis in vitro by studying wellcharacterized markers of apoptosis, such as annexin- $\mathrm{V} /$ propidium iodide (IP) binding, activation of caspase-3, cytochrome $\mathrm{c}$ and Fas receptor expression in human CD4+ T lymphocytes.

\section{Materials and Methods}

\subsection{Monocyte Locomotion Inhibitory Factor (MLIF)}

MLIF (Met-Gln-Cys-Asn-Ser), 96\% pure was obtained commercially (American Peptide Co., Sunnyvale, CA, USA). All working solutions were tested for endotoxin (LPS $<0.3 \mathrm{pg}$ ) using the limulus assay (Amoebocyte Lysate Endosafe KTA Charles River Endosafe INC, Charleston, Inc, USA) and were kept at $-70^{\circ} \mathrm{C}$ until use.

\subsection{Cell Purification}

Thirty milliliters of heparinized venous blood was obtained from healthy, non-smoking adult volunteers of both sexes. Blood was diluted 1:2 with phosphate buffered saline (PBS; $0.15 \mathrm{M}$ phosphate buffer), then $10 \mathrm{ml}$ of the sample was layered over $4 \mathrm{ml}$ of a Ficoll-Hypaque (Sigma Chemical Co., St. Louis, MO) gradient $(\delta=$ 1.077) and centrifuged at $700 \times \mathrm{g}$ for $30 \mathrm{~min}$ at $21^{\circ} \mathrm{C}$ [18]. Peripheral blood mononuclear cells (PBMC) at the interface were removed and washed twice with PBS. CD4+ T cells were purified using the CD4+ T Cell Isolation Kit II (Miltenyi Biotec, Germany) an indirect magnetic labelling system for the isolation of untouched $\mathrm{CD} 4+\mathrm{T}$ cells from human PBMCs, with LS columns and a MidiMACS separator. Briefly, $1 \times 10^{7}$ PBMC were placed in polypropylene tubes with $80 \mu \mathrm{l}$ of PBS-albumin-EDTA and $20 \mu \mathrm{l}$ a cocktail of biotin-conjugated antibodies against CD8, CD11b, CD16, CD19, CD36, CD56, CD123, $\mathrm{TCR} \gamma / \delta$ and CD235a (glycophorin A), and were incubated for $10 \mathrm{~min}$ at $4^{\circ} \mathrm{C}$. These cells were subsequently magnetically labelled with Anti-Biotin MicroBeads for depletion. The population of CD4+ $\mathrm{T}$ lymphocytes that was isolated was $95 \%$ pure.

\subsection{Cell Culture}

Five $\times 10^{5} \mathrm{CD} 4+\mathrm{T}$ cells were placed in 24-well plates in: 1) RPMI-1640 medium alone (supplemented with $10 \%$ fetal calf serum (FCS), $2 \mathrm{mM}$ L-glutamine, $100 \mathrm{U} / \mathrm{ml}$ streptomycin, $5 \mu \mathrm{g} / \mathrm{ml}$ gentamicin, and $1 \mathrm{mM}$ sodium pyruvate) (Gibco Laboratories, Grand Island, NY, USA); 2) in medium supplemented with $50 \mathrm{ng} / \mathrm{ml}$ phorbol 12-myristate 13-acetate (PMA) (Sigma, Chemical Co, St. Louis MO); 3) in medium with $50 \mu \mathrm{g} / \mathrm{ml}$ MLIF; 4) PMA + MLIF; or 5) $1 \mu \mathrm{g} / \mathrm{ml}$ actinomycin $\mathrm{D}$ for $24 \mathrm{~h}$ at $37^{\circ} \mathrm{C}$, $5 \% \mathrm{CO}_{2}$ [19]. Cell viability was $\geq 90 \%$ by trypan blue dye (Sigma) exclusion. The optimal concentrations of MLIF and PMA were determined from dose-response curves.

\subsection{Annexin V/Propidium Iodide Double Staining by Flow Cytometry}

For annexin V/propidium iodide (PI) double staining, cells were resuspended in $100 \mathrm{ml}$ of binding buffer $(10$ $\mathrm{mM} N$-(2-hydroxyethyl) piperazine- $N$-2-ethanesulfonic acid (HEPES)/ $\mathrm{NaOH}, 140 \mathrm{mM} \mathrm{NaCl}, 2.5 \mathrm{mM} \mathrm{CaCl} 2, \mathrm{pH}$ 7.4) and stained with $5 \mathrm{ml}$ of both FITC-conjugated annexin V and PI (BD Biosciences). The mixture was incubated for $15 \mathrm{~min}$ at room temperature in the dark, followed by flow cytometry analysis. Acquisition of 10,000 events was conducted in flow cytometry FACScalibur (BD Biosciences, Palo Alto, CA). For analysis, Win MDI 
2.8 software was used.

\subsection{Quantitation of Total Cytochrome $\mathrm{c}$ in Cultured Cells}

After a $24 \mathrm{~h}$ incubation in the presence of medium alone, PMA, PMA + MLIF or actinomycin D the CD4+ T cells were harvested in their culture medium, pelleted by centrifugation at $300 \times \mathrm{g}$ for $15 \mathrm{~min}$, rinsed with PBS, and resuspended in Cell Lysis Buffer 2 (Cell Lysis Buffer 2 solubilises the cytochrome $\mathrm{c}$ in both the cytosol and mitochondria) to a final concentration of $1.5 \times 10^{6} \mathrm{cell} / \mathrm{s} / \mathrm{ml}$. The cell lysate was incubated for $1 \mathrm{~h}$ and centrifuged at $1000 \times \mathrm{g}$ for $15 \mathrm{~min}$. The resulting supernatant cytochrome $\mathrm{c}$ was measured with a quantitative sandwich enzyme immunoassay technique (cytochrome c ELISA Kit) (Calbiochem ${ }^{\circledR}$ Merck KGaA, Darmstadt, Germany). Plates were pre-coated with a monoclonal antibody specific for cytochrome c. Standards and samples were pipetted into coated wells, and cytochrome $\mathrm{c}$ was bound to the immobilised antibody. After washing, an enzymelinked monoclonal antibody specific for cytochrome c was added to each well, followed by the substrate. In this assay, the colour develops in proportion to the amount of cytochrome $\mathrm{c}$ bound in the initial step. Colour development was stopped, and the intensity of the colour was measured. The quantity of human cytochrome $\mathrm{c}$ was determined as a change in absorbance at $450 \mathrm{~nm}$ using a microplate reader (Dynatech MR 5000, Maryland, USA).

\subsection{Quantitation of Activated Human Caspase-3}

Caspase- 3 activity was measured by using a human active caspase 3 ELISA kit protocol (OptEIA ${ }^{\mathrm{TM}}$, BD Biosciences). Briefly, cells were lysed in a hypotonic buffer (10 mM HEPES [pH 7.4], $50 \mathrm{mM} \mathrm{NaCl}, 2 \mathrm{mM} \mathrm{MgCl} 2,5$ mM EGTA, $1 \mathrm{mM}$ phenylmethylsulfonyl fluoride, and protease inhibitor cocktail). After incubating for $45 \mathrm{~min}$ on ice, lysates were centrifuged at $40,000 \times \mathrm{g}$ for $45 \mathrm{~min}$ at $4^{\circ} \mathrm{C}$. Cell lysates were diluted with $200 \mu \mathrm{l}$ assay diluent buffer (50 mM HEPES [pH 7.4], 0.2\% CHAPS \{3-[(3-cholamidopropyl)-dimethylammonio]-1-propanesulfonate \}, 20\% glycerol, $2 \mathrm{mM}$ EDTA, $10 \mathrm{mM}$ dithiothreitol), was added to each well and incubated for $2 \mathrm{~h}$ at room temperature. Next, $100 \mu \mathrm{l}$ of cytochrome c standard or sample was added to each well and incubated for $2 \mathrm{~h}$. Subsequently, $100 \mu \mathrm{l}$ of horseradish peroxidase-conjugated streptavidin (1X) and $100 \mu \mathrm{l}$ of substrate solution were added to each well and incubated for $30 \mathrm{~min}$. Finally, $50 \mu \mathrm{l}$ of stop solution was added to each well. The absorbance of the cleaved substrate at $450 \mathrm{~nm}$ was measured with a microplate reader (Dynatech MR 5000, Maryland, USA).

\subsection{Quantification of Fas in the Supernatant of Cultured Cells}

The presence of Fas in the supernatant fluids of cultured CD4+ $\mathrm{T}$ lymphocytes $\left(1 \times 10^{6}\right.$ cells/well $)$ was determined and quantified using an ELISA kit with an antibody that recognises human Fas (Ray Biotech, Inc., Atlanta, Georgia), according to the manufacturer's instructtions. For calibration, we used a commercially available, natural human Fas protein to construct a standard curve and to obtain absolute values. The concentration of Fas was measure in six independent assays per treatment, each in duplicate, and the average of the six measurements was considered to be the final concentration.

\subsection{Statistical Analysis}

All values were expressed as mean \pm standard deviation (SD). Commercial SPSS v. 11.0 for Windows (SPSS Inc., Chicago, IL) was used for statistical analysis. Statistical comparisons between groups were performed using the Mann-Whitney $U$ tests; $p$ values $\leq 0.05$ were deemed statistically significant.

\section{Results}

\subsection{Detection of Apoptosis by Annexin V/Propidium Iodide Staining}

To determine whether apoptosis was induced by MLIF, and to discriminate between early apoptosis and necrosis, cells were simultaneously stained with annexin V and PI. Human CD4+ T lymphocytes were cultured in the presence of RPMI medium (negative control), MLIF, MLIF, PMA or PMA + MLIF, and actinomycin D served as the positive control. Results showed that $7 \%$ of CD4+ T lymphocytes underwent spontaneous apoptosis in the medium control. When the cells were stimulated with MLIF, 9\% of CD4+ T lymphocytes stained positive for annexin V. When stimulated with PMA, a significant number of cells $(13 \%)$ were apoptotic $(\mathrm{p}<0.003 \mathrm{com}-$ pared to medium control), and among cells treated with PMA+MLIF, the frequency of apoptosis was 10\% (not significant, NS). Actinomycin D treatment increased early apoptosis to $19 \%$ of cells ( $p<0.0001$ compared to medium control) (Figure 1). However, in the analysis of late apoptosis, PMA + MLIF significantly increased the binding of annexin $\mathrm{V}$ ( $21 \%$ of cells) compared to the control $(11 \%, \mathrm{p}<0.002)$ (Figure 1), suggesting that the pro-apoptotic activity of MLIF + PMA is related to the extrinsic signalling pathway and/or the intrinsic pathway of apoptosis.

\subsection{Production of Cytochrome $c$ and Fas (APO-1)}

PMA + MLIF may favour activation-induced cell death. 

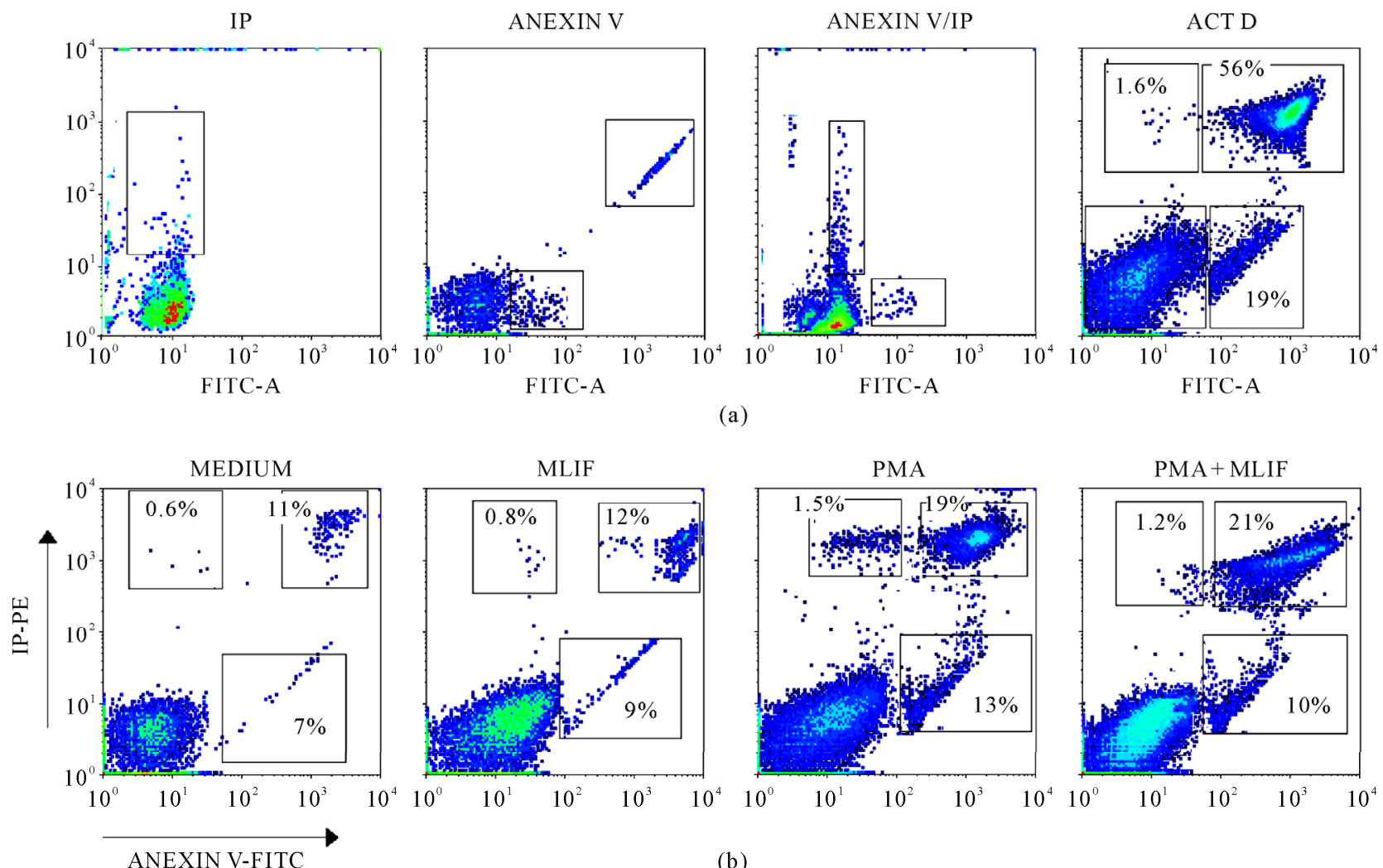

(b)
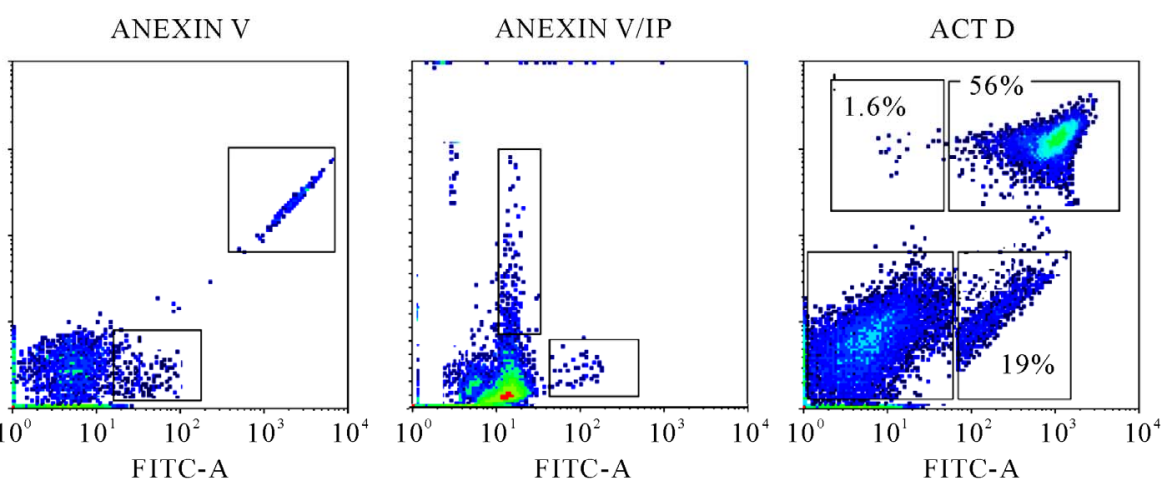

Figure 1. Apoptosis in CD4+ T lymphocytes. Lymphocytes were cultured for $24 \mathrm{~h}$ in RPMI-1640 medium alone (control) or in RPMI medium containing MLIF alone, PMA alone, PMA + MLIF or actinomycin D. Cells were stained with FITC-conjugated annexin $\mathrm{V}$ and propidium iodide (annexin/IP) and processed for cell death determination by flow cytometry. (a) Calibration parameters and positive control (actinomycin D); (b) The numbers in each quadrant of the flow cytometry histograms represent the mean percentage of six independent experiments. The percentage of necrotic cells is indicated in the upper left quadrant; apoptotic-necrotic cells, in the upper right quadrant; and early apoptotic cells in the lower right quadrant.

Non-stimulated CD4 $+\mathrm{T}$ cells (RPMI medium control) produced $9 \mu \mathrm{g} / \mathrm{ml}$ of cytochrome c; cells stimulated with MLIF produced $12 \mu \mathrm{g} / \mathrm{ml}$; with PMA, $15 \mu \mathrm{g} / \mathrm{ml}$; with PMA + MLIF, $19 \mu \mathrm{g} / \mathrm{ml}$; and with actinomycin D, 33 $\mu \mathrm{g} / \mathrm{ml}$ (Figure 2). MLIF per se did not stimulate the release cytochrome c (NS), but treatment with PMA + MLIF resulted in a there was a statistically significant difference compared to the negative control $(\mathrm{p}<0.001)$ and positive control $(\mathrm{p}<0.0001)$, suggesting that the intrinsic pathway of apoptosis is activated. Actinomycin $\mathrm{D}$ produced a greater increase in the release of cytochome c (Figure 2). In contrast, Fas receptor expression was not observed under any of the treatment conditions (data not shown).

\subsection{Determination of Activated Human Caspase-3}

Execution of apoptosis requires the activation of the caspase cascade, where activated initiator caspases cleave and thereby trigger downstream effector caspases that, in turn, dismantle the cell. Whereas proteolytic cleavage of an effector caspase is indicative of its activation, the same is not necessarily true with initiator caspases.

We wondered whether the effect of MLIF on the expression of cytochrome c converged upon the caspase-3 pathway. In cells treated with medium alone, basal expression of caspase-3 was $90 \mathrm{U} / \mathrm{ml}$ (Figure 3). Exposure to MLIF increased expression of caspase- 3 to $110 \mathrm{U} / \mathrm{ml}$, and upon PMA treatment, was $196 \mathrm{U} / \mathrm{ml}$. In cells treated with PMA + MLIF caspase-3 production was $235 \mathrm{U} / \mathrm{ml}$, and with actinomycin D, it was $329 \mathrm{U} / \mathrm{ml}$. As expected, actinomycin $\mathrm{D}$ treatment was significantly different $(\mathrm{p}<$ 0.002) compared to basal levels (Figure 3) and cells treated with MLIF, PMA, PMA + MLIF ( $<<0.001, \mathrm{p}<$ 0.0001 and $\mathrm{p}<0.01$ respectively). The signalling cascade of caspase 3 was different between groups, and this stronger between the PMA and actinomycin D.

\section{Discussion}

Apoptosis can be induced either as a consequence of key 


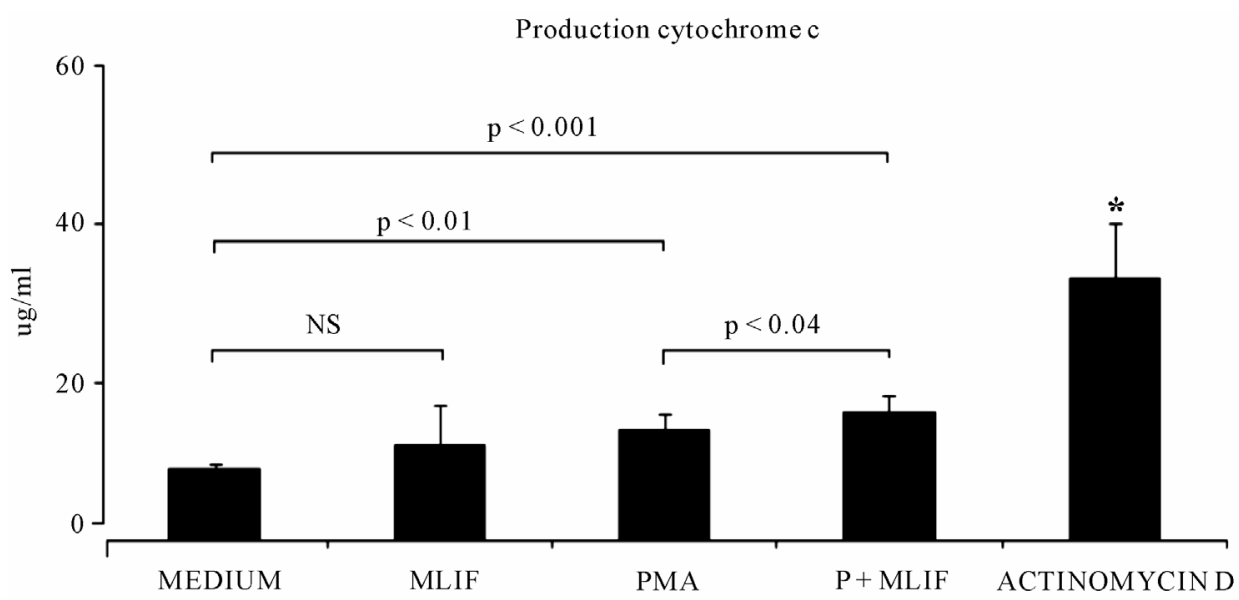

Figure 2. Quantification of cytochrome c. One $\times 10^{5}$ CD4+ T lymphocytes, cultured in the presence of PMA, MLIF or PMA + MLIF for $24 \mathrm{~h}$, were lysed and centrifuged at $4000 \times \mathrm{g}$, and cytochrome $\mathrm{c}$ in the supernatant was measured. Histograms show mean values \pm SD of six independent experiments. Statistically significant differences between all groups and actinomycin $D$ are indicated with an asterisk, $p<0.05$ (Mann-Whitney test).

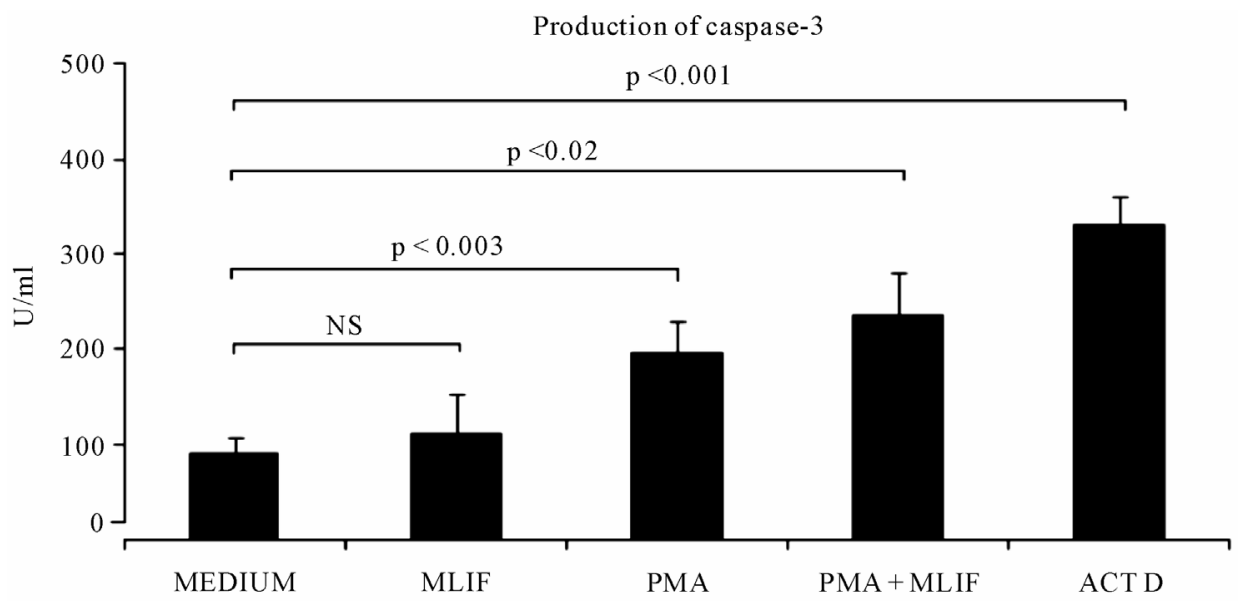

Figure 3. Quantification of caspase-3. After culturing under the indicated conditions, $10^{5}$ lymphocytes were lysed and centrifuged at $4000 \times$ g. Released caspase- 3 in the supernatant was measured using a commercially available enzyme-linked immunosorbent assay (ELISA) kit. The levels of caspase- 3 are represented as means of caspase-3 concentrations vs the negative control group, or the positive control group (actinomycin D) in cells treated with MLIF, PMA, PMA + MLIF (p $<0.001$, p $<$ 0.0001 and $p<0.01$ respectively). $\mathrm{NS}=$ no significant difference, $\mathrm{n}=6, \mathrm{p}<0.05$ (Mann-Whitney Test).

proteins being released into the cytosol by the mitochondria or by the activation of a death receptor on the cell surface. Both signalling pathways converge at the level of effector caspases, without causing the inflammation produced by necrotic cell death [20].

Infection with $E$. histolytica is associated with an acute inflammatory response [21]. However, it is not completely clear how E. histolytica modulates the pro-inflammatory response of the host. Previous work studying the effect of MLIF on inflammation, specifically the inhibition of interleukins, such as IL- 2 , IFN- $\gamma$ and IL- $1 \beta$, indicates that MLIF acts selectively in different cell lineages. At least two possible explanations could ac- count for this effect: MLIF may either inhibit soluble pro-inflammatory or regulate apoptosis mediators [22, 23].

In this study, we determined that MLIF per se does not induce programmed cell death in human CD4+ T lymphocytes, as demonstrated in early apoptosis. Cell death was slightly increased in the presence of PMA (MLIF + PMA) but was detected only in late apoptosis (apoptosis/ necrosis). MLIF has powerful but selective anti-inflammatory properties; this peptide inhibits locomotion (random, chemotactic and chemokinetic) of normal human peripheral blood mononuclear phagocytes in response to various chemoattractants, such as C5a-desArg, lym- 
phokine chemotactic or lymphocyte-derived chemotactic factor (LDCF), but has no effect on polymorphonuclear neutrophils [12]. MLIF is capable of downregulating some pro-inflammatory cytokines, including IFN- $\gamma$, IL-2, and IL-6, and of inducing the anti-inflammatory cytokines IL-4 and IL-10 [22]. MLIF delays the arrival of mononuclear leukocytes into Rebuck chambers applied to the skin of healthy human volunteers [12]. In this study, the combination of PMA + MLIF caused an increased susceptibility to late apoptosis in lymphocytes, implicating the intrinsic apoptosis signalling pathway. This increase may illustrate an additive effect because PMA-dependent apoptosis was also slightly increased in the late apoptosis. The intracellular apoptosis machinery depends on caspases, which are proteases responsible for executing programmed cell death. Once activated, a caspase will in turn activate the next pro-caspase downstream, creating a proteolytic amplification cascade. Some of the activated caspases cleave other key proteins in the cell, such as those that form the nuclear lamina and the cytoskeleton, leading to the destruction of the nuclear framework, and activate DNases that degrade nuclear DNA. These changes underlie the nuclear and cytoplasmic structural modifications that occur in apoptotic cells $[24,25]$. Release of cytochrome c from mitochondria is an important step in mitochondria-mediated apoptosis; it leads to the activation of caspase 9 and then caspase 3 [26]. The fact that the Fas receptor was absent from the surface of MLIF-treated T cells suggests that there was no death receptor activation. Although Fas is mostly thought of as a death receptor that is capable of inducing the apoptosis of activated T cells via the caspase cascade [27], this receptor has also been implicated in effective $T$ cell activation. Fas could act as a receptor with functional pleiotropy in models of T cell [28]. MLIF interacts with human leukocytes through a mannose-containing receptor [29], and it causes an increase in the number of pericentriolar microtubules and in the cAMP concentration, without a concomitant reduction in cGMP [30]. In U-937 cells, MLIF inhibits the expression of inflammatory cytokines, such as MIP- $1 \alpha$ and MIP- $1 \beta$, which are NF- $\kappa$ B pathway-regulated proteins, as was described by Utrera-Barillas [31]. The p65-p50 heterodimer comprises the most abundant form of NF- $\kappa$ B in a PMA-induced system. Temporary studies showed that MLIF induces p50 translocation, which could be due to the fact that MLIF stimulates cAMP synthesis and phosphorylation of NF- $\kappa$ B by protein kinase A, phosphorylation of $\mathrm{I} \kappa \mathrm{B}$ and subsequent NF- $\kappa \mathrm{B}$ translocation [32]. MLIF strongly inhibits inflammation but does not induce early apoptosis, downregulates the Fas receptor, activate caspase 3 or trigger the release of cytochrome $\mathrm{c}$, indicating that it is largely non-cytotoxic, however; we must be caution in extrapolating these results to other population of lymphocytes such as CD8+ $\mathrm{T}$ cells and regulatory $\mathrm{T}$ cells.

We propose that this is a novel natural anti-inflammatory molecule produced in axenic cultures of $E$. histolytica that, owing to its small size (five peptides), is nonantigenic, thus making it a strong candidate for future clinical applications.

\section{Acknowledgements}

This research was supported, in part, by a grant from the Consejo Nacional de Ciencia y Tecnología, (CONACYT): No. 089657. The authors wish to thank Verónica Vrátný Zuleta for the critical review of the English language in the manuscript. The authors are grateful to laboratory technician José de la Luz Romero Preciado from the Blood Bank in the Centro Médico Nacional Siglo-XXI-IMSS, México City, México.

\section{REFERENCES}

[1] P. Marrack, T. Mitchell, J. Bender, D. Hildeman, R. Kedl, K. Teague and J. Kappler, "T-Cell Survival," Immunological Reviews, Vol. 165, No. 1, 1998, pp. 279-285. doi:10.1111/j.1600-065X.1998.tb01245.X

[2] J. P. Medema, "Apoptosis-Life and Death in a FLASH," Nature, Vol. 398, No. 5, 1999, pp. 756-757. doi: $10.1038 / 19638$

[3] C. Klas, K. M. Debatin, R. R. Jonker and P. H. Krammer, "Activation Interferes with the APO-1 Pathway in Mature Human T Cells," International Immunology, Vol. 5, No. 6, 1993, pp. 625-630. doi:10.1093/intimm/5.6.625

[4] G. M. Bran, J. Stern-Strater, K. Hörmann, F. Riedel and U. R. Goessler, "Apoptosis in Bone for Tissue Engineering," Archives of Medical Research, Vol. 39, No. 5, 2008, pp. 467-482. doi:10.1016/j.arcmed.2008.02.007

[5] D. J. Van Antwerp, S. J. T. Martin, Kafri, D. R. Green and I. M. Verma, "Suppression of TNF-Alpha-Induced Apoptosis by NF-kB," Science, Vol. 274, No. 5288, 1996, pp. 787-789. doi:10.1126/science. 274.5288 .787

[6] C. Scaffidi, S. Fulda, A. Srinivasan, C. Friesen, F. Li, K. J. Tomaselli, K. M. Debatin, P. H. Krammer and M. E. Peter, "Two CD95 (APO-1/Fas) Signaling Pathways," The EMBO Journal, Vol. 17, No. 6, 1998, pp. 1675-1687. doi:10.1093/emboj/17.6.1675

[7] D. R. Schultz and W. J. Harrington, "Apoptosis: Programmed Cell Death at a Molecular Level," Seminars in Arthritis and Rheumatism, Vol. 32, No. 6, 2003, pp. 345369. doi:10.1053/sarh.2003.50005

[8] Y. S. Ki, E. Y. Park, H. W. Lee, M. S. Oh, Y. W. Cho, Y. K. Kwon, J. H. Moon and K. T. Lee, "Donepezil, a Potent Acetylcholinesterase Inhibitor, Induces Caspase-Dependent Apoptosis in Human Promyelocytic Leukemia HL-60 Cells," Biological \& Pharmaceutical Bulletin, Vol. 
33, No. 6, 2010, pp. 1054-1059.

doi:10.1248/bpb.33.1054

[9] A. Lawen, "Apoptosis-An Introduction 2," Bioassay, Vol. 25, No. 9, 2003, pp. 2013-2026. doi:10.1002/bies.10329

[10] K. W. Tinsley, D. Herzog and D. Leitenberg, "CD4 Co-Receptor Dependent Signaling Promotes Competency for Re-Stimulation Induced Cell Death of Effector T Cells," Cellular Immunology, Vol. 266, No. 2, 2011, pp. 200-207. doi:10.1016/j.cellimm.2010.10.006

[11] T. Miyawaki, T. Uehara, R. Nibu, T. Tsuji, A. Yachie, S. Yonehara and N. Taniguchi "Differential Expression of Apoptosis-Related Fas Antigen on Lymphocyte Subpopulations in Human Peripheral Blood," The Journal of Immunology, Vol. 149, No. 11, 1992, pp. 3753-3758.

[12] R. R. Kretschmer, M. L. Collado, M. Pacheco, M. Salinas, M. Lopéz-Osuna, M. Lecuona, E. Castro and J. Arellano, "Inhibition of Human Monocyte Locomotion by Products of Axenically Grown E. histolytica," Parasite Immunology, Vol. 7, No. 5, 1985, pp. 527-543. doi:10.1111/j.1365-3024.1985.tb00097.x

[13] G. Rico, O. Diaz-Guerra, J. A. Giménez-Scherer and R. R. Kretschmer, "Effect of the Monocyte Locomotion Inhibitory Factor (MLIF) Produced by Entamoeba histolytica upon the Respiratory Burst of Human Leukocytes," Archives of Medical Research, Vol. 23, No. 2, 1992, pp. 157-159.

[14] G. Rico, E. Leandro, S. Rojas, J. A. Giménez and R. R. Kretschmer, "The Monocyte Locomotion Inhibitory Factor Produced by Entamoeba histolytica Inhibits Induced Nitric Oxide Production in Human Leukocytes," Parasitology Research, Vol. 90, No. 4, 2003, pp. 264-267. doi:10.1007/s00436-002-0780-7

[15] J. A. Giménez-Scherer, G. Rico-Rosillo, J. FernándezDíez and R. R. Kretschmer, "Inhibition of Contact Cutaneous Delayed Hypersensitivity Reactions to DNBC in Guinea Pigs by the Monocyte Locomotion Inhibitory Factor (MLIF) Produced by Axenically Grown Entamoeba histolytica," Archives of Medical Research, Vol. 28, No. 4, 1997, pp. 237-238.

[16] J. A. Giménez-Scherer, G. Cárdenas, M. López-Osuna, J. R. Velázquez, G. Rico, A. Isibasi, M. C. Maldonando, M. E. Morales, J. Fernandez-Díez J and R. R. Kretschmer, "Immunization with a Tetramer Derivative of an Anti-Inflammatory Pentapeptide Produced by Entamoeba histolytica Protects Gerbils (Meriones unguiculatus) against Experimental Amoebic Abscess of the Liver," Parasite Immunol, Vol. 26, No. 8, 2004, pp. 343-349. doi:10.1111/i.0141-9838.2004.00718.x

[17] C. Soriano-Correa, J. F. Sanchez-Ruiz, G. Rico-Rosillo, J. A. Giménez-Scherer, J. R. Velázquez and R. Kretschmer, "Electronic Structure and Physicochemical Properties of the Anti-Inflammatory Pentapeptide Produced by Entamoeba histolytica: Theoretical Study," Journal of Molecular Structure: THEOCHEM, Vol. 769, No. 91, 2006, pp. 91-95. doi:10.1016/j.theochem.2006.02.031

[18] A. Böyum, "Isolation of Mononuclear Cells and Granu- locytes from Human Blood," Scandinavian Journal of Clinical Laboratory Investigation, Vol. 97, No. 97, 1968, pp. 77-89.

[19] R. Freshney, "Scaling-Up of Animal Cell Cultures," In: D. Rickwood and B. D. Hames, Culture of Animal Cells: A Manual of Basic Technique, Alan R. Liss, Inc., New York, 1987, pp. 47-92.

[20] D. R. Green, "Apoptotic Pathways: The Roads to Ruin," Cell, Vol. 94, No. 6, 1998, pp. 695-698. doi.10.1016/S0092-8674(00)81728-6

[21] K. Chadee and E. Meerovitch, "The Pathogenesis of Experimentally Induced Amebic Liver Abscess in the Gerbil (Meriones unguiculatus)," The American Journal of Pathology, Vol. 117, No. 1, 1984, pp. 71-80.

[22] S. Rojas-Dotor, G. Rico, J. Pérez, J. Velázquez and R. Kretschmer, "Cytokine Expression in CD4+ Cells Exposed to the Monocyte Locomotion Inhibitory Factor Produced by Entamoeba histolytica," Parasitology Research, Vol. 98, No. 5, 2006, pp. 493-495. doi.10.1007/s00436-005-0090-y

[23] S. Rojas-Dotor, J. Pérez-Ramos, J. A. Giménez-Scherer, F. Blanco-Favela and G. Rico-Rosillo, "Effect of the Monocyte Locomotion Inhibitory Factor (MLIF) Produced by E. histolityca on Cytokines and Chemokine Receptors in T CD4+ Lymphocytes," Biological Research, Vol. 42, No. 4, 2009, pp. 415-425.

[24] S. Yonehara, A. Ishii and M. Yonehara, "A Cell-Killing Monoclonal Antibody (Anti-Fas) to a Cell Surface Antigen Co-Downregulated with the Receptor of Tumor Necrosis Factor," The Journal of Experimental Medicine, Vol. 169, No. 5, 1989, pp. 1747-1756. doi:10.1084/jem.169.5.1747

[25] B. C. Trauth, A. M. Peters, S. Matzku, P. Möller, W. Falk, K. M. Debatin and P. H. Krammer, "Monoclonal Antibody-Mediated Tumor Regression by Induction of Apoptosis," Science, Vol. 245, No. 4915, 1989, pp. 301-305. doi:10.1126/science. 2787530

[26] G. A. Porter and R. Jänicke, "Emerging Roles of Caspase-3 in Apoptosis," Cell Death and Differentiation, Vol. 6, No. 2, 1999, pp. 99-104. doi: $10.1038 /$ sj.cdd. 4400476

[27] J. P. Medema and J. Borst, "T Cell Signaling: A Decision of Life and Death," Human Immunology, Vol. 60, No. 5, 1999, pp. 403-411. doi:10.1016/S0198-8859(99)00008-7

[28] E. O'Flaherty, W. K. Wong, S. J. Pettit, K. Seymour, S. Ali and J. A. Kirby, "Regulation of T-Cell Apoptosis: A Mixed Lymphocyte Reaction Model," Immunology, Vol. 100 , No. 3, 2000, pp. 289-299. doi:10.1046/j.1365-2567.2000.00048.x

[29] R. R. Kretschmer, E. M. Castro, G. Pacheco, G. Rico, O. Diaz-Guerra and J. Arellano, "The Role of Mannose in the Receptor of the Monocyte Locomotion Inhibitory Factor Produced by Entamoeba histolytica," Parasitology Research, Vol. 77, No. 5, 1991, pp. 374-378. doi:10.1007/BF00931631

[30] G. Rico, O. Díaz-Guerra and R. Kretschmer, "Cyclic 
Nucleotide Changes Induced in Human Leukocytes by a Product of Axenically Grown Entamoeba histolytica That Inhibits Human Monocyte Locomotion," Parasitology Research, Vol. 81, No. 5, 1995, pp. 158-162. doi:10.1007/BF00931623

[31] D. Utrera-Barrillas, J. R. Velázquez, A. Enciso, S. M. Cruz, G. Rico, E. Curiel-Quezada, L. M. Terán and R. Kretschmer, "An Anti-Inflammatory Oligopeptide Produced by Entamoeba histolytica Down-Regulates the Ex- pression of Pro-Inflammatory Chemokines," Parasite Immunology, Vol. 25, No. 10, 2003, pp. 475-482. doi:10.1111/j.1365-3024.2003.00657.x

[32] R. Kretschmer, J. Velázquez, D. Utreras-Barillas and A. Zentella, "The Amebic Anti-Nflammatory Monocyte Locomotion MLIF Inhibits the NF-kB Nuclear Translocation in Human Monocytes," The FASEB Journal, Vol. 18, No. 8, 2004, p. A1147. 